\title{
Study on Thermal-Hydraulic Behavior of an Integral Type Reactor under Heaving Condition
}

\author{
Beibei Feng, ${ }^{1}$ Xingtuan Yang, ${ }^{1}$ Shengqiang Li, ${ }^{1}$ Yanfei Sun, \\ Jiyuan Tu, ${ }^{1,2}$ and Shengyao Jiang ${ }^{1}$ \\ ${ }^{1}$ Key Laboratory of Advanced Reactor Engineering and Safety, Ministry of Education of China, \\ Institute of Nuclear and New Energy Technology, Tsinghua University, Beijing 100084, China \\ ${ }^{2}$ Shool of Aerospace, Mechanical \& Manufacturing Engineering, RMIT University, Plenty Road, Bundoora, VIC 3083, Australia \\ Correspondence should be addressed to Shengyao Jiang; jiangshy@tsinghua.edu.cn
}

Received 5 November 2013; Revised 20 February 2014; Accepted 20 February 2014; Published 8 April 2014

Academic Editor: Luciano Burgazzi

Copyright (C) 2014 Beibei Feng et al. This is an open access article distributed under the Creative Commons Attribution License, which permits unrestricted use, distribution, and reproduction in any medium, provided the original work is properly cited.

\begin{abstract}
A self-developed program was used to study the thermal-hydraulic behavior of an integral type reactor under heaving condition. Comparison of calculated results with the data of experiments performed on a natural circulation loop designed with reference to an integral type reactor of Tsinghua University in inclination, heaving, and rolling motions was carried out. Characteristics of natural circulation in heaving motion and effect of motion parameters on natural circulation were investigated. Results indicated that: (1) long-period heaving motion would lead to more significant influence than inclination and rolling motion; (2) it was an alternating force field which consisted of gravity and an additional force that decided the flow temperature and density difference of natural circulation; (3) effect of strength $k$ and cycle $T$ of heaving motion on flow fluctuation of natural circulation and condensate depression of heating section outlet was performed.
\end{abstract}

\section{Introduction}

Integral type reactor with its coolant system components in reactor vessel has wide applications due to its passive safety property. $5 \mathrm{MW}$ experimental low temperature nuclear heating reactor (NHR) of Tsinghua University is a low-power integral type reactor with modular and self-stabilization which has been applied to the engineering fields of heat supply and seawater desalination $[1,2]$. As part of the studies responding to the application of NHR as ship power, Institute of Nuclear and New Energy Technology (INET) of Tsinghua University built an experimental loop with reference to NHR to investigate the effect of rolling motion and inclination motion (two typical oceanic movements) on natural circulation [3-5]. A program was also developed to provide a tool for investigating the effect of heaving motion (the third typical oceanic movement) on natural circulation which could not realized through the experimental loop.

On land, successful operation of NHR has proved the feasibility of its technical solutions. Under oceanic conditions, it needs revalidation through experiments resulting from the effect of oceanic environment on thermal-hydraulic behavior of natural circulation due to the additional movements caused by oceanic motions, such as rolling, heaving, and inclination. So, INET built a rolling experimental apparatus with reference to NHR to simulate oceanic motions, which consisted of a symmetrical two-circuit test loop and auxiliary equipment [6, 7]. Geometric parameters of experimental rolling apparatus was designed completely the same as NHR to investigate the effect of same strength of oceanic motion on natural circulation, and operation parameters were arranged the same as NHR. Due to the restriction of experimental rolling apparatus, effect of heaving motion on thermal-hydraulic behavior of natural circulation could not be investigated experimentally and a self-developed program was accordingly developed to accomplish this work. The aim of the present paper was to describe our comprehensive analysis results concerning natural circulation under heaving motion and effect of motion parameters on natural circulation obtained using the self-developed program. Comparison 
of effect of inclination motion and rolling motion on natural circulation between calculation and experimental data was conducted to validate the self-developed program. A heaving strength parameter $k$ was proposed to describe heaving motion in alternating force field. Flow rate and condensate depression of natural circulation under heaving motion with various cycle $T$ and strength $k$ were investigated in detail.

\section{Experimental System}

2.1. Similarity Analysis. For two similar physical phenomena, parameters describing the law of the phenomena should be proportionable. Similarity analysis is carried out for catching the dynamics of the coupled physics. In order to guarantee a more clear and comparable comprehension to NHR, mathematical equations of experimental system should have the same solution as NHR. Criteria numbers deduced from momentum equation, energy equation, and thermal boundary condition could be obtained as follows:

$$
\begin{gathered}
S_{t}=\frac{L}{V \cdot t}, \quad F_{r}=\frac{V^{2}}{g \cdot L}, \\
E_{u}=\frac{P}{\rho \cdot V^{2}}, \quad R_{e}=\frac{\rho V L}{\mu}, \\
P_{e}=\frac{\rho c V L}{\lambda}, \\
N_{u}=\frac{\partial L}{\lambda} .
\end{gathered}
$$

For the issue of single-phase flow and heat transfer process, the experimental apparatus and NHR are equivalent when the above criteria numbers are the same. For the heat exchange process of natural circulation, density difference induced by flow temperature and height difference drive the natural circulation. So, Grashof number should be introduced:

$$
G_{r}=\frac{g \beta \Delta T L^{3}}{v^{2}}
$$

2.2. Experimental Apparatus. The experimental setup is made up of three loops (as shown in Figure 1(a)). Test section in experiments is a symmetrical two-circuit loop (primary loop) which is designed exactly based on NHR's structure provided with the same height and width. Primary loop equals to a cut from NHR in the diameter direction, as shown in Figure 1(b). Experimental condition parameters are arranged the same as NHR to simulate the actual environment and achieve high comparative accuracy.

Primary loop consisted of heating section, upper plenum, steam generator, downcomer, and lower plenum. A rolling test bench is built to fix primary loop and oceanic motions, such as rolling and inclination, could be achieved through the movement of the test bench driven by two motors. Three electric heaters $(\mathrm{EH})$ located at the shared part of the two circuits supply the heat source with outlet temperature $220^{\circ} \mathrm{C}$. To meet the requirement of heating power, heater tubes are divided into two groups of eight tubes each with $75 \mathrm{~V} \mathrm{DC}$ operating voltage and $3.7 \mathrm{Kw}$ single-robust power would be achieved. The arrangement of heater tubes and electrifying mode is shown in Figure 1(c). Two double-pipe heat interchangers located on the upper part of each circuit were used, but the amount of heat exchange tubes was reduced proportionality to ensure same heat load on heat exchange area as NHR. The primary loop was mounted on a ship motions simulation platform and could achieve rolling motion with maximum angles of $45^{\circ}$ and $20^{\circ}$ in $x$ direction and in $y$ direction, respectively. The working fluid of the primary loop was demineralized water with a pressure of 4.0 $\mathrm{MPa}$.

The secondary loop consisted of a pump, a heat exchanger, two mixers, and a pressurizer. The coolant for the secondary loop was water driven by a pump rather than natural circulation. The mixer and control valves were used to equally set the coolant temperature and flow rates of the two circuits in order to avoid an unbalanced load. The secondary loop was kept at high pressure $(4.0 \mathrm{MPa})$ to prevent the occurrence of two-phase flow due to the simplicity of the equipment. The pressurizer was filled with high-pressure nitrogen gas in order to adjust and maintain the pressure. The main equipment for the third loop was the cooling tower, through which heat input from the secondary loop was finally emitted into the environment with the coolant circulation.

Main shape and operation parameters are listed in Table 1. Compared with public experimental studies, testing section in this work is designed with following characteristics.

(a) A symmetrical two-circuit loop which simulate natural circulation of an actual reactor under oceanic motions is more reasonable.

(b) Same height and width of primary loop as NHR will reflect the real strength of rolling motion.

(c) Operation parameters of primary loop are arranged the same as NHR to simulate NHR's operation.

\section{Calculation Model and Validation}

3.1. Mathematical Model. Mathematical model based on the analysis of experimental system was built first [8-10]. To simplify handling natural circulation in heaving condition, coordinate system was established on the experimental apparatus. It was mathematically an issue in noninertial reference frame of natural circulation under heaving condition. An inertia force was brought into the fluid particle momentum equation in heaving condition resulting from the additional force of oceanic motions.

Continuity equation is as follows:

$$
\frac{\partial \rho}{\partial t}+\nabla \cdot(\rho \vec{V})=0
$$

Momentum equation is as follows:

$$
\frac{D \vec{V}}{D t}=\vec{f}-\frac{1}{\rho} \nabla P+\frac{1}{\rho} \nabla \cdot(2 \mu S) .
$$




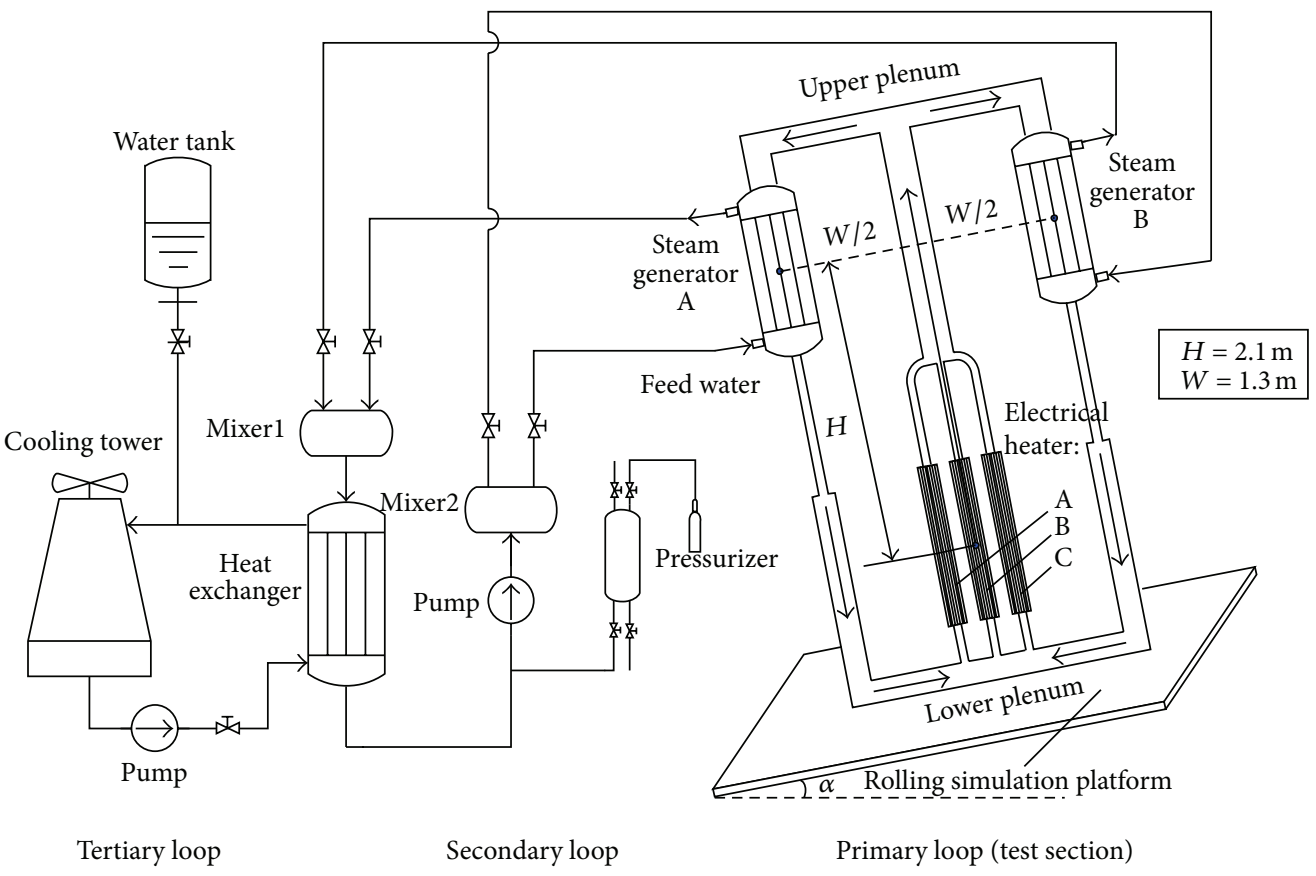

(a)

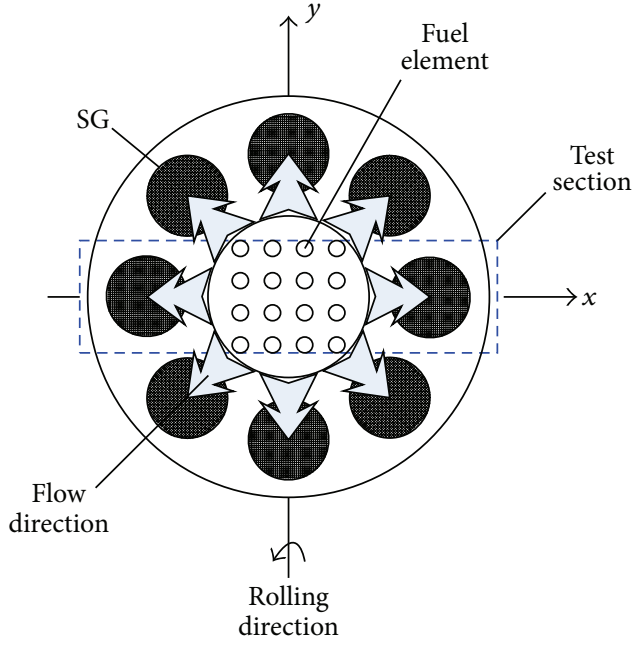

(b)

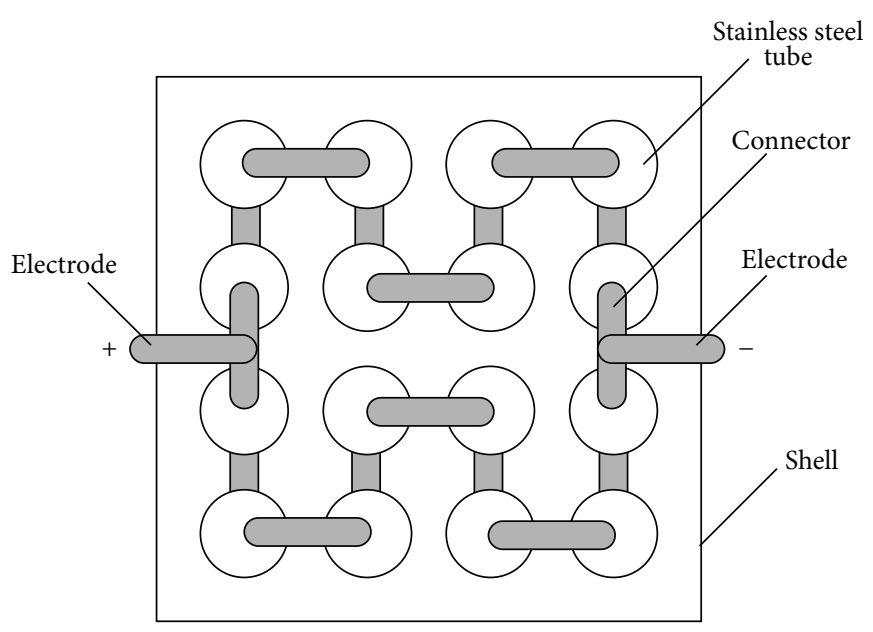

(c)

FIGURE 1: Experimental apparatus [6].

Energy equation is as follows:

$$
\rho C \frac{D T}{D t}=\nabla \cdot(\lambda \nabla T),
$$

where $\rho, f, \mu$, and $\lambda$ were the density, mass force, viscosity, and thermal conductivity of the fluid and $S$ was rate of strain tensor.

$$
\vec{f}=\vec{g}-\vec{a}_{o}-\overrightarrow{\dot{w}} \times \vec{r}-\vec{w} \times(\vec{w} \times \vec{r})-2 \vec{w} \times \vec{V}_{r},
$$

where $g$ was acceleration of gravity and $\vec{a}_{o}=d^{2} \vec{r}_{o} / d t^{2}$ as an additional force induced by the translational motion of experimental apparatus in $x, y$, and $z$ direction. $\vec{a}_{t}=\overrightarrow{\dot{w}} \times \vec{r}$ was tangential force; $\vec{a}_{n}=\overrightarrow{\dot{w}} \times(\overrightarrow{\dot{w}} \times \vec{r})$ was normal force; and $\vec{a}_{c}=2 \overrightarrow{\dot{w}} \times \vec{V}_{r}$ was Coriolis force.

In the case of one-dimensional flow, the Coriolis force was negligible. Assume that $a_{o z}=\mathrm{kg} \cdot \sin \left(w_{d} \cdot t\right)$; thus $g-a_{o z}=$ $\left(1-k \sin \left(w_{d} \cdot t\right)\right) \cdot g$.

Heaving motion was the vertical translational motion which was in the same direction of gravity. So, $\left(g-a_{o z}\right)$ could be treated as alternating gravitational field which was viewed as the product of acceleration of gravity $g$ and a time-varying coefficient $\left(1-k \sin \left(w_{d} \cdot t\right)\right)$.

Relative velocity of natural circulation to experimental apparatus was used to describe natural circulation in the above formulas. Symmetric double circulation of primary 
TABLE 1: Comparison of operation parameters of experimental apparatus and NHR.

\begin{tabular}{|c|c|c|c|}
\hline & $\begin{array}{l}\text { Power } \\
(\mathrm{Kw})\end{array}$ & $\begin{array}{c}\text { Pressure bearing capacity } \\
(\mathrm{MPa})\end{array}$ & $\begin{array}{l}\text { Inlet/outlet temperature of } \\
\text { heating section }\left({ }^{\circ} \mathrm{C}\right)\end{array}$ \\
\hline \multicolumn{4}{|c|}{ Experimental apparatus } \\
\hline Operation value & 163.054 & 5.0 & $179.8 / 210.1$ \\
\hline Design value & 164 & 5.0 & $180 / 211$ \\
\hline \multirow[t]{2}{*}{ NHR } & $3 \times 10^{4}$ & 5.0 & $180 / 211$ \\
\hline & $\begin{array}{c}\text { Temperature difference between } \\
\text { inlet and outlet of heating section } \\
\left({ }^{\circ} \mathrm{C}\right)\end{array}$ & $\begin{array}{l}\text { Average temperature of heating } \\
\text { section }\left({ }^{\circ} \mathrm{C}\right)\end{array}$ & $\begin{array}{l}\text { Outlet velocity of heating section } \\
\qquad\left(\mathrm{m} \cdot \mathrm{s}^{-1}\right)\end{array}$ \\
\hline \multicolumn{4}{|c|}{ Experimental apparatus } \\
\hline Operation value & 30.4 & 194.95 & 0.3619 \\
\hline Design value & 31 & 195.5 & 0.37321 \\
\hline \multirow[t]{2}{*}{ NHR } & 31 & 195.5 & 1 \\
\hline & $\begin{array}{l}\text { Outlet velocity of heat exchanger } \\
\qquad\left(\mathrm{m} \cdot \mathrm{s}^{-1}\right)\end{array}$ & $\begin{array}{l}\text { Natural circulation flow } \\
\left(\mathrm{kg} \cdot \mathrm{s}^{-1}\right)\end{array}$ & Amount of fuel rod \\
\hline \multicolumn{4}{|c|}{ Experimental apparatus } \\
\hline Operation value & 0.4292 & 1.2062 & 48 \\
\hline Design value & 0.4318 & 1.2404 & 1 \\
\hline \multirow[t]{2}{*}{ NHR } & 1 & 227 & 8784 \\
\hline & Amount of heat exchangers & Type of heat exchanger & $\begin{array}{c}\text { Experimental apparatus/NHR } \\
\text { ratio } \\
\end{array}$ \\
\hline \multicolumn{4}{|c|}{ Experimental apparatus } \\
\hline Operation value & 2 & Telescopic & $1 / 183$ \\
\hline Design value & 1 & 1 & I \\
\hline NHR & 18 & Telescopic & 1 \\
\hline
\end{tabular}

loop that consisted of two inner circuits, one outer circuit, and three mediate channels was observed, as shown in Figure 2. F101, F102, and F103 were used to mark the right heating section, the mediate heating section and the left heating section of primary loop, respectively, and F104, F105 were used to mark the two-side heat exchangers.

3.2. Program Verification. Verification of the developed program was carried out through comparison between calculation results and the data of experiments on land and in rolling, inclination conditions. For one-dimensional natural circulation, the key factor was whether the calculated flow resistance was consistent with the experimental results. So, calculated flow resistance would be modified through experiments to make sure of the correction of program. Then, use this program to calculate natural circulation in heaving condition.

Figures 3 and 4 plotted the comparison of experimental results and calculated results of rolling motion with swing angle $\psi_{m}=22.5^{\circ}$ and rolling cycle $T=13 \mathrm{~s}$ in zero-power condition and in hot state, respectively. It can be inferred that curves of calculated results were almost the same as that of experimental results of rolling motion with swing angle $\psi_{m}=22.5^{\circ}$ and rolling cycle $T=13$ s in zero-power condition and of rolling motion with swing angle $\psi_{m}=45^{\circ}$ and rolling cycle $T=18 \mathrm{~s}$ in full-power condition.

\section{Results and Discussion}

4.1. Characteristics of Natural Circulation in Heaving Motion. Reference [8] has reported the experimental verification of natural circulation of an actual reactor on land. The program has been proved to be correct through the comparison with experimental data. Comparison of flow characteristics of natural circulation on land with heaving motion was conducted to study the effect of heaving motion on natural circulation.

The additional force induced by heaving motion was acting on natural circulation in a parallel field of force. Effect of heaving motion exhibited a symmetry property for a symmetrical natural circulation loop. Figure 5 plotted the flow and condensate depression of channel outlet of the left and the intermediate heating section in heaving motion with strength $\left(g-a_{o z}\right)=0.4 \mathrm{~g}$ and cycle $T=13 \mathrm{~s}$. Dotted line in Figure 5 was the dynamic time-average value in steady heaving motion. Figure 6 plotted the flux of primary side of heat exchanger and condensate depression of outlet of secondary side.

Experimental results indicated the following.

(1) Flux of natural circulation, outlet temperature of heating section, and temperature of secondary side of the heat exchanger will rise and fall in the same period as heaving motion. The value of fluctuate cycle was about $13 \mathrm{~s}$ as shown in Figures 5 and 6. 


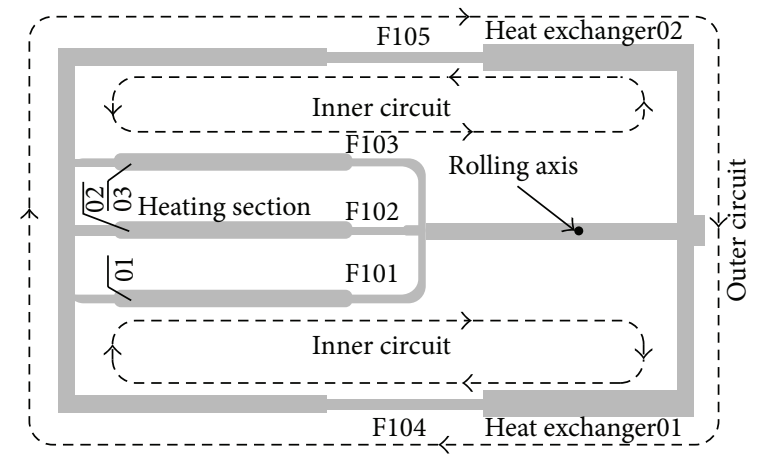

FIGURE 2: Structure of primary loop consisted of inner circuit and outer circuit.

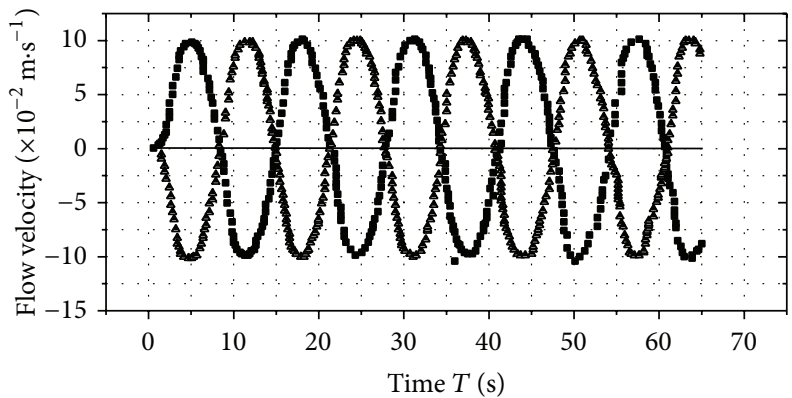

- F103

๑ F101

- F102

(a)

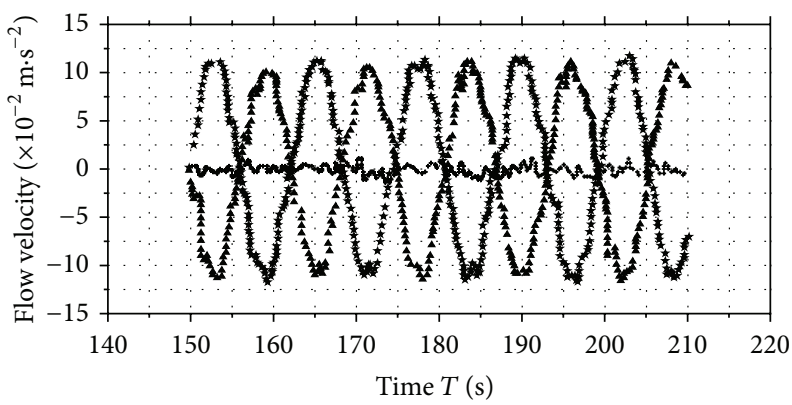

$\star \mathrm{F} 101$

. F103

- F102

(b)

FIGURE 3: Comparison of experimental results and calculated results of rolling motion with swing angle $\psi_{m}=22.5^{\circ}$ and rolling cycle $T=13 \mathrm{~s}$ in zero-power condition: (a) calculated result; (b) experimental result.

(2) The flux and flow temperature of left heating section were the same as that of the intermediate heating section which indicated that the uniform distribution of flow was realized on the bottom of reactor core. Slight difference of flux and temperature were generated from the resistance of channel bend.

(3) In heaving motion, time-average value of relative flux of heating section and the part of heat exchangers was both less than 1 which indicated a decreased capability of natural circulation of the primary loop. The amount of reduction was about $5 \%$ in heaving motion with strength $\left(g-a_{o z}\right)=0.4 \mathrm{~g}$ and cycle $T=13 \mathrm{~s}$.

4.2. Mechanism of Natural Circulation in Heaving Motion. Heaving motion of the experimental apparatus would result in an additional force acting on the natural circulation which 


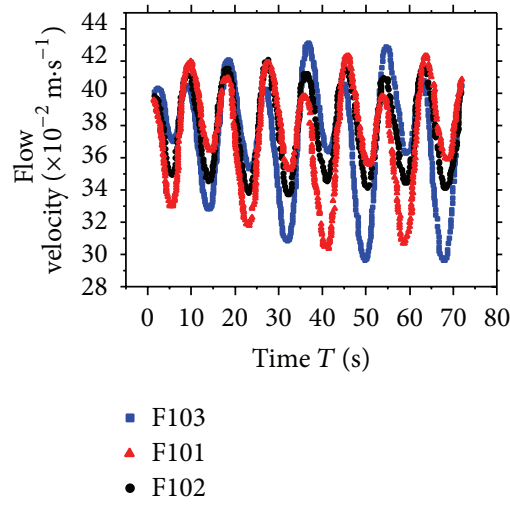

(a)

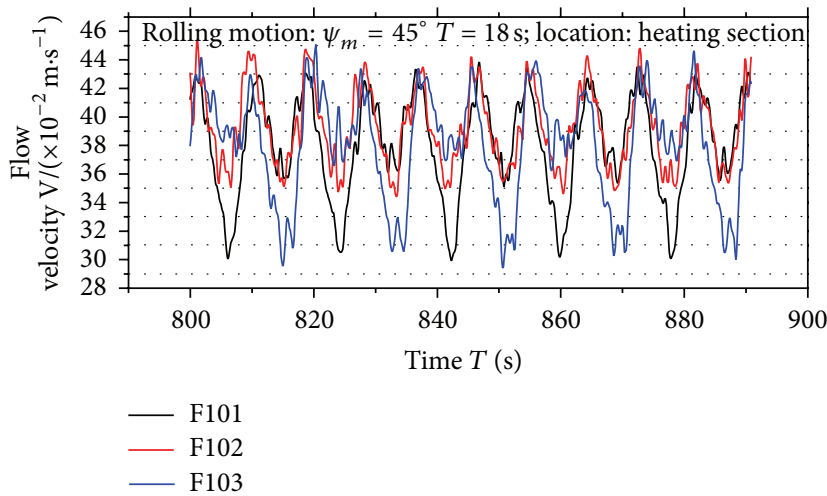

(b)

Figure 4: Comparison of experimental results and calculated results of rolling motion with swing angle $\psi_{m}=45^{\circ}$ and rolling cycle $T=18 \mathrm{~s}$ in full power condition: (a) calculated result; (b) experimental results.

was parallel to gravity. Fixing the coordinate system on the experimental apparatus, natural circulation in heaving motion could be the issue in the noninertia coordinate system and treated as natural circulation under alternating vertical force field which could be calculated through the following formula:

$$
g-a_{o z}=\left(1-k \sin \left(w_{d} \cdot t\right)\right) \cdot g
$$

The driving force of natural circulation could be expressed as

$$
\Delta P_{d}=\Delta \rho(t)\left(1-k \sin \left(w_{d} \cdot t\right)\right)
$$

where $\Delta \rho(t)$ was the time-varying density difference between the hot fluid and the cold fluid. The driving force of natural circulation in heaving motion included the gravity and an additional force resulting from the heaving motion. Slight flow density difference in the primary loop could be achieved in the case of low level of temperature fluctuation caused by heaving motion. If the above factor was ignored, flow rate of natural circulation in heaving motion could be equal to the superposition of the steady flow and the additional flow resulting from the heaving motion. Gravity and the induced force were independent and the effect on natural circulation could be superposed of the two above force directly. In the case of stronger flow temperature difference resulting from heaving motion, the former superposition was not correct in this case any more. Compared with the steady natural circulation on land, flow fluctuation in heaving motion would result in flow density difference. Simultaneously, flow density difference affects the driving force of natural circulation. Consequently, natural circulation in strong heaving motion was a result of alternating force field and flow density field.

Figure 7 plotted the relationship chain of factors affecting natural circulation in heaving motion: the alternating field which consisted of gravity and additional force would drive natural circulation. Flow fluctuation resulting from the alternating field would cause the flow temperature fluctuation which resulted in flow density difference. Further, density difference simultaneously affected the driving force of natural circulation. Accordingly, flux of natural circulation changed. Relationship of the factors affecting natural circulation was illustrated in Figure 7.

\subsection{Effect of Heaving Cycle and Heaving Strength on Natural} Circulation. Considering the effect of heaving motion on natural circulation, a heaving item $a_{o z}=k \cdot g \cdot \sin \left(w_{d} \cdot t\right)$ was imported into the momentum equation, where $w_{d}=2 \pi / T$. 


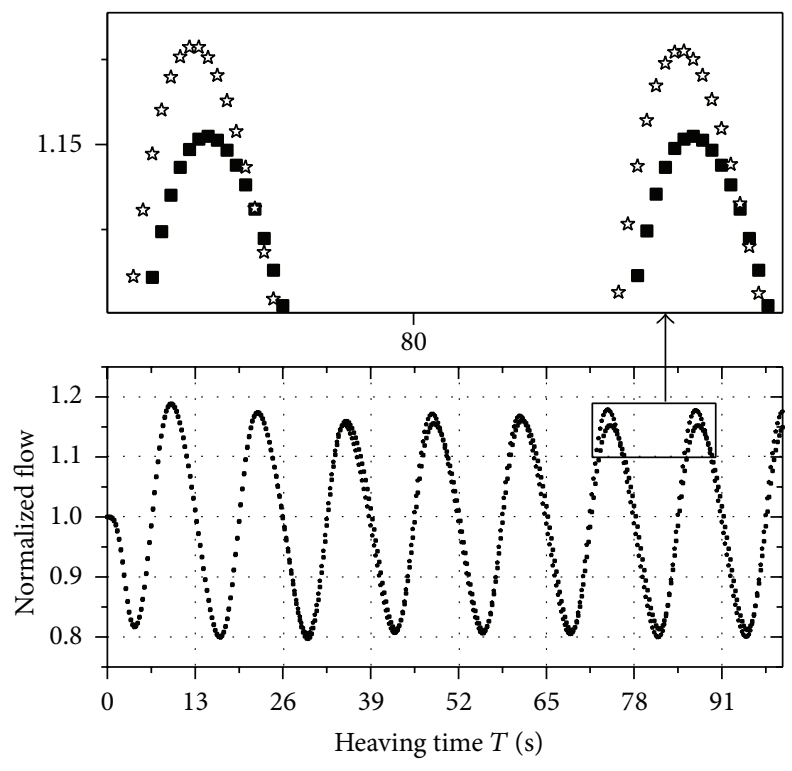

- F101/F103

\& $\mathrm{F} 102$

(a)

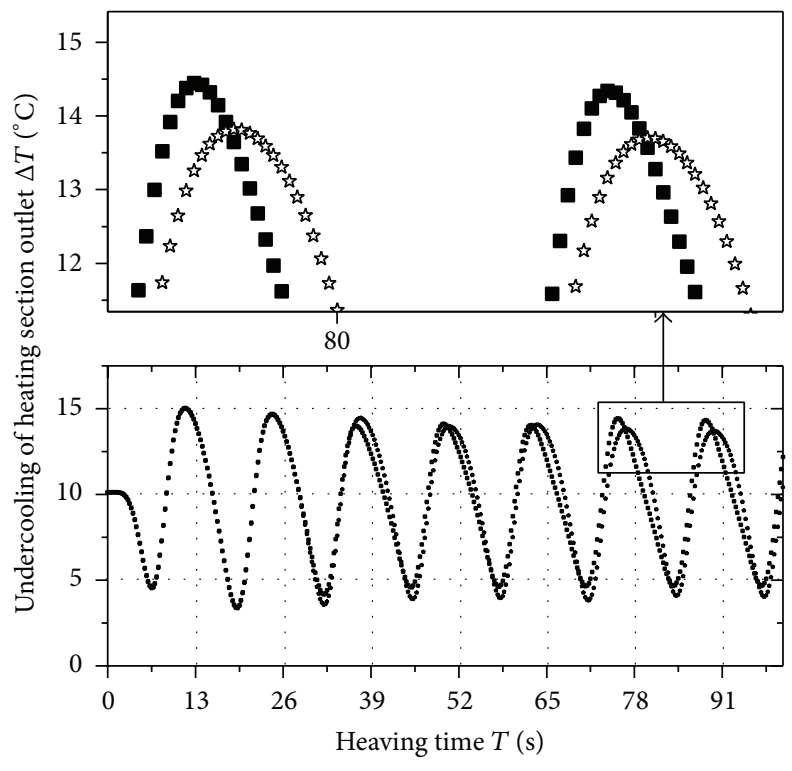

- F101/F103

क $\mathrm{F} 102$

(b)

FIGURE 5: Flow and condensate depression of channel outlet of the left and the intermediate heating section in heaving motion with strength $\left(g-a_{o z}\right)=0.4 \mathrm{~g}$ and cycle $T=13 \mathrm{~s}$ : (a) normalized flow; (b) condensate depression.

So, flow velocity and displacement would be calculated through the following equations:

$$
\begin{aligned}
& V_{o z}=-\frac{k g}{\bar{w}_{d}} \cdot k \cdot g \cdot \cos \left(\bar{w}_{d} \cdot t\right), \\
& A_{o z}=-\frac{k g}{\bar{w}_{d}} \cdot k \cdot g \cdot \sin \left(\bar{w}_{d} \cdot t\right) .
\end{aligned}
$$

It can be inferred that phase of displacement of heaving motion was inverted to acceleration and the amplitude was proportional to frequency squared. The parameter $k$ was proposed to describe the strength of heaving motion.

Figure 8 plotted the flux of natural circulation, condensate depression of heating section's outlet, and the secondary side of heat exchanger under heaving motion with cycle 


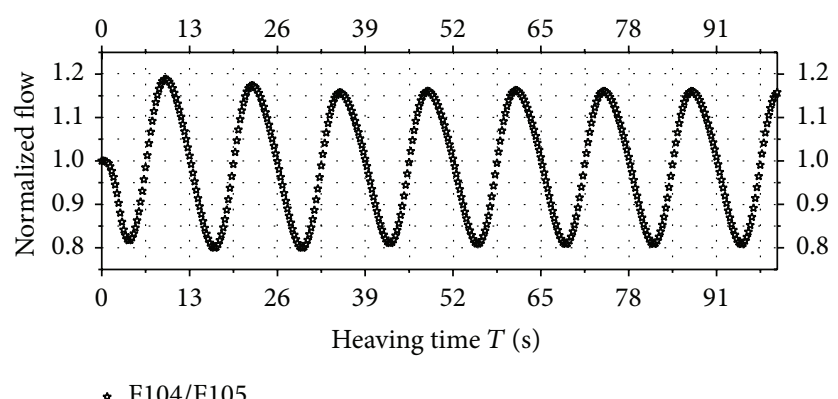

(a)

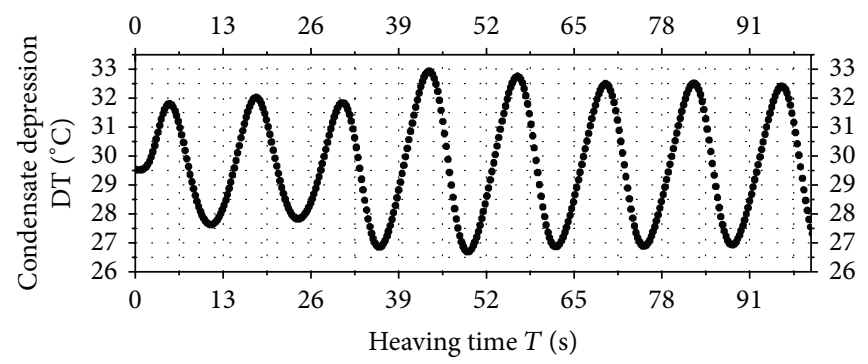

- Outlet of secondary side

(b)

FIGURE 6: Flux of primary side of heat exchanger and condensate depression of outlet of secondary side: (a) normalized flow; (b) condensate depression.

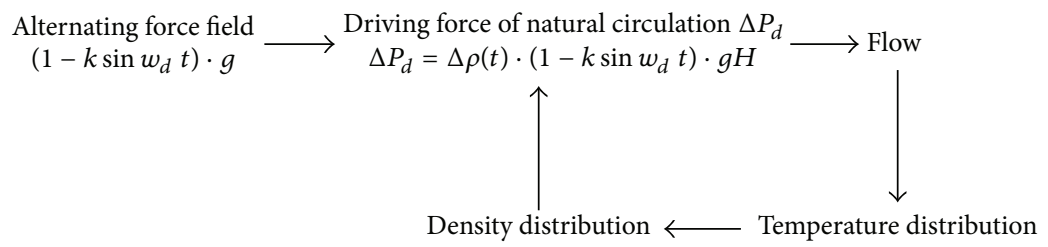

FIGURE 7: Relationship chain of factors affecting natural circulation in heaving motion.

$T=3 \mathrm{~s}$ and $k=0.2,0.4,0.6$, respectively. Results indicated the following.

(1) Fluctuation of flux and temperature would be stronger with the increasing heaving strength. When heaving strength $\left(g-a_{o z}\right)=0.6 \mathrm{~g}$ and cycle $T=3 \mathrm{~s}$, fluctuation of flux was up to $17 \%$.

(2) Changes of the condensate depression of heating section's outlet exhibited regular fluctuation along with the heaving motion experiencing several heaving motion cycles with the start of steady state on land, as shown in Figure 8(b). In the initial stage, the inlet temperature of heating section kept constant while about $17 \%$ flow fluctuation was observed in the process of fluid flowing into heating section channel from the down comer. Accordingly, condensate depression of heating section's outlet exhibited serious fluctuation in the first heaving cycle. Weaker temperature fluctuation of heating section's outlet and the secondary side of heat exchanger was achieved in the later transitory stage. This was because the temperature of heating section's outlet was decided by inlet temperature and flux fluctuation which would go weaker with the end of transitory stage.

While $k$ was constant, the flow and temperature of natural circulation would exhibit similar fluctuation with the variational cycles of heaving motion. In Figure 9, the peak and valley of natural circulation were given. Flow fluctuation would rise nonlinearly with the heaving cycle $T$ changing from $3 \mathrm{~s}$ to $8 \mathrm{~s}$ when heaving strength $k$ was constant. Longer heaving cycle meant that the additional force generating from heaving motion would act on natural circulation in a longer period of time which led to bigger flow change and thermal saturation, or even boiling. Figure 10 plotted the calculated results of condensate depression of heating section outlet in heaving motion with strength $k=0.6$ and cycle $T=3 \mathrm{~s}, 8 \mathrm{~s}$, $13 \mathrm{~s}, 18 \mathrm{~s}$, and $23 \mathrm{~s}$, respectively. Results indicated an obvious fluctuation of temperature with heaving cycle changing from $3 \mathrm{~s}$ to $8 \mathrm{~s}$. When heaving cycle $T=8 \mathrm{~s}$, the temperature difference from peak to valley was about $16^{\circ} \mathrm{C}$. The critical point of heaving cycle was $T=13 \mathrm{~s}$ when heaving strength 


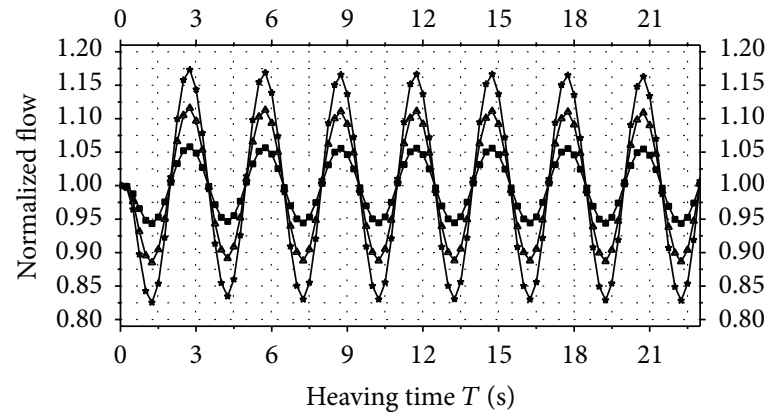

(a)

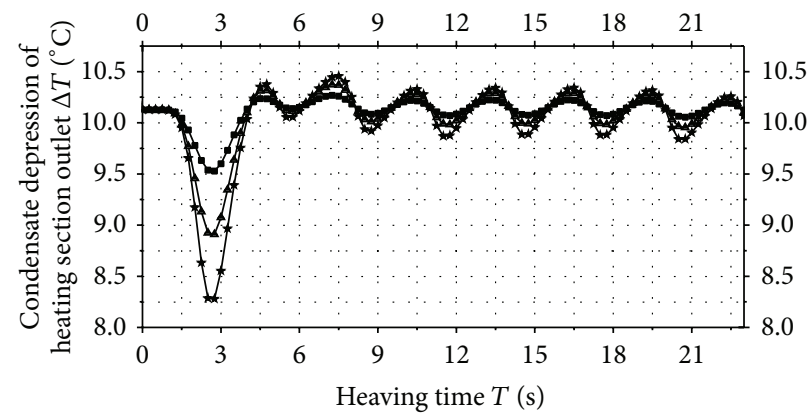

(b)

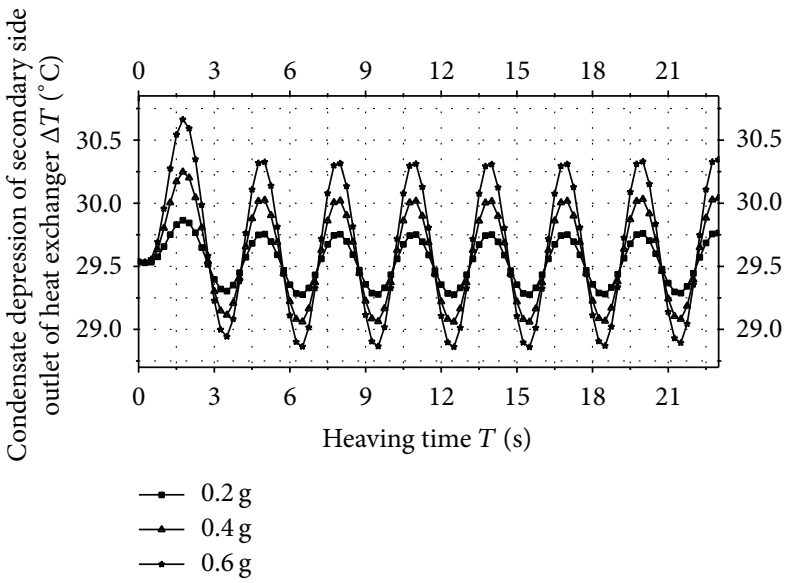

(c)

Figure 8: Flux of natural circulation, condensate depression of heating section's outlet, and the secondary side of heat exchanger under heaving motion with cycle $T=3 \mathrm{~s}$ and $k=0.2,0.4$, and 0.6 : (a) flux of natural circulation; (b) condensate depression of heating section's outlet; (c) secondary side of heat exchanger.

$k=0.6$ : there was no thermal saturation when $T<13 \mathrm{~s}$, but thermal saturation when $T>13 \mathrm{~s}$.

Little effect of short -cycle heaving motion (for instance $T=3 \mathrm{~s}$ ) on natural circulation was observed, while significant effect, or even serious accident, would occur under heaving motion with long cycle.

4.4. Comparison of Characteristics of Natural Circulation in Heaving, Inclination, and Rolling Motions. Effect of basic oceanic movements, such as heaving motion, inclination, and rolling motion on natural circulation was investigated through the program and experiments. Comparison of experimental results and simulation results of natural circulation under inclination was carried out, as shown in Figure 11. Total amount of natural circulation decreased slightly, while the flow going through one heat exchanger would increase, but another would decrease under inclination condition, which was related to the resistance characteristics, geometric parameters, and facility arrangement of the experimental apparatus. Under inclination with tilt angle $45^{\circ}, 12 \%$ reduction of the total amount of natural circulation was achieved. From Figure 12, little effect of inclination on natural circulation was observed through comparison of calculated results with experimental data. 


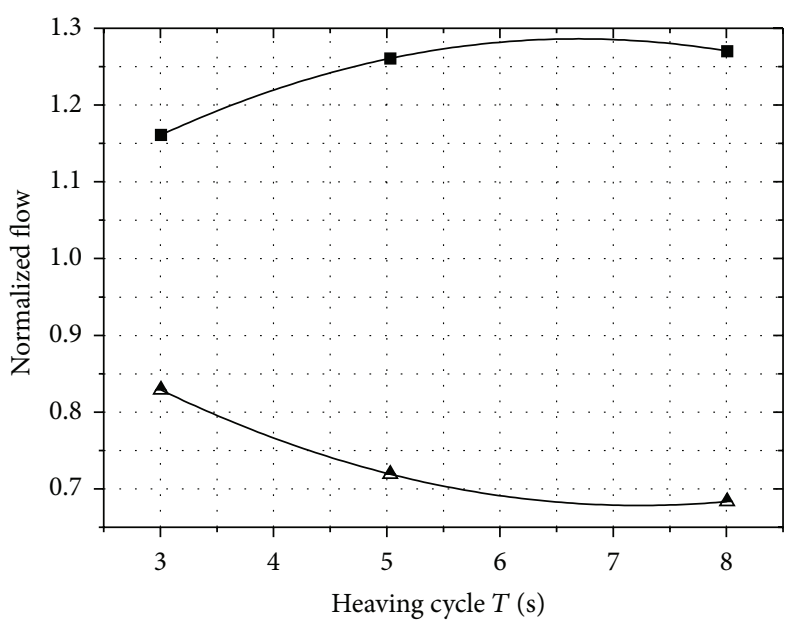

- Peak flow

$\Delta$ Valley flow

FIGURE 9: Peak and valley of flow changes of natural circulation with variable heaving cycle $T$ when heaving strength $k=0.6$.

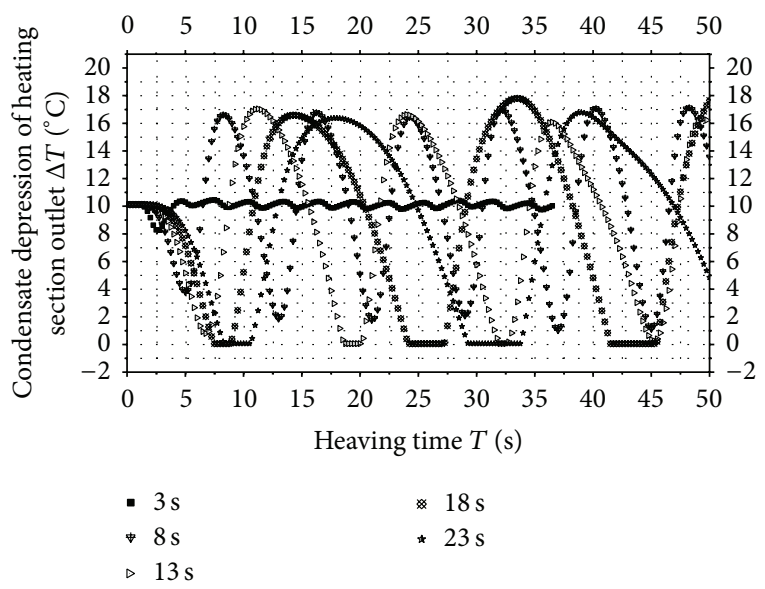

FIGURE 10: Calculated results of condensate depression of heating section outlet in heaving motion with strength $k=0.6$ and cycle $T=3 \mathrm{~s}, 8 \mathrm{~s}, 13 \mathrm{~s}, 18 \mathrm{~s}$, and $23 \mathrm{~s}$.

Effect of heaving motion with strength $0.6 \mathrm{~g}$ and cycle $8 \mathrm{~s}$, vertical rolling with swing angle $22.5^{\circ}$ and cycle $8 \mathrm{~s}$, compound motions which consisted of the above two movements, heaving motion with strength $0.6 \mathrm{~g}$ and cycle $8 \mathrm{~s}$, transverse rolling with swing angle $22.5^{\circ}$ and cycle $13 \mathrm{~s}$, and compound motion which consisted of the above two movements on the normalized flow of natural circulation was shown in Figure 12. Rolling motion along the axis parallel to this page was defined as vertical rolling motion, and rolling motion along the axis perpendicular to this page was defined as transverse rolling motion. An increase of flow fluctuation was observed compared heaving motion $0.6 \mathrm{~g}, 8 \mathrm{~s}$ with vertical rolling $13 \mathrm{~s}, 22.5^{\circ}$. And, stronger effect of the compound motion consisted of the mentioned heaving motion and rolling motion on natural circulation was confirmed. Due to the identical cycle of vertical rolling motion and heaving

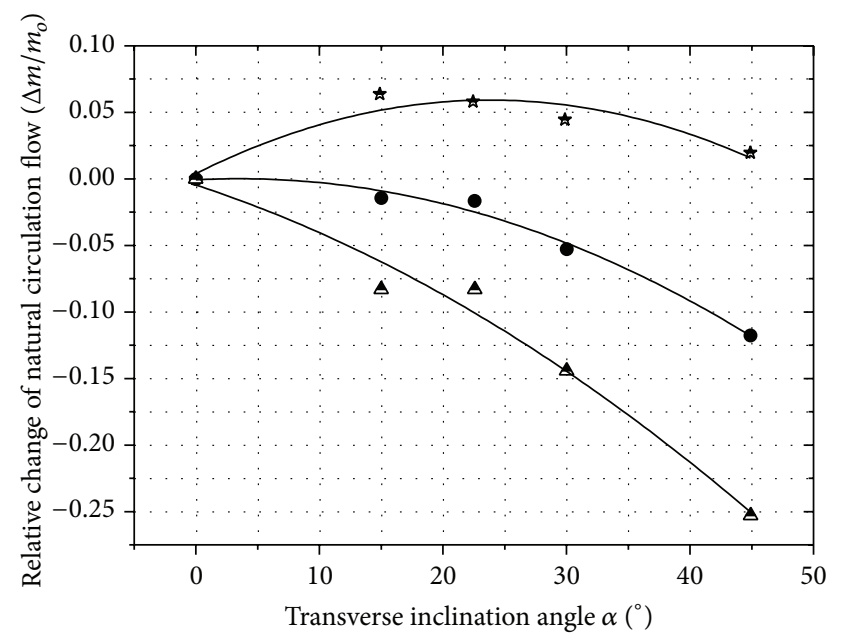

Experimental result

$\star \Delta M_{21} /\left(\Delta M_{21}\right)_{o}$

- $\Delta M_{22} /\left(\Delta M_{22}\right)_{o}$

$\Delta \Delta M_{2} /\left(\Delta M_{2}\right)_{o}$

FIGURE 11: Comparison of experimental results and simulation results of natural circulation in inclination condition with different angles.

motion, cycle of natural circulation in the combination of the above two movements was synchronous. Considering the effect of heaving motion and transverse rolling, much stronger fluctuation of natural circulation in heaving motion with strength $0.6 \mathrm{~g}$ and cycle $8 \mathrm{~s}$ was observed than in transverse rolling motion with swing angle $22.5^{\circ}$ and cycle $13 \mathrm{~s}$. Stronger fluctuation could be predicted in heaving motion with cycle $13 \mathrm{~s}$. A complex flow waveform resulting from the motion of heaving together with transverse rolling was observed and the heaving component was considered the main driving factor. Same flow fluctuation cycle was observed as the cycle of heaving component, and magnitude of flow fluctuation would be affected by the transverse component.

For large-scale ships, oceanic low frequency motion would lead to significant effect on natural circulation. Longperiod rolling motion took slight effect on natural circulation due to small amount of the induced additional force which inclination could be treated as a special type of rolling motion with infinite cycle. But long-period heaving motion would lead to significant effect on natural circulation. Through the comparison, we could find out that long-period heaving motion may lead to the worst effect on natural circulation than inclination and rolling motion.

\section{Conclusion}

The comparison of calculated results with experimental data on a natural circulation loop designed with reference to $5 \mathrm{MW}$ experimental low temperature nuclear heating reactor of Tsinghua University in inclination, heaving, and rolling motions was carried out. Flow characteristics and effect of motion parameters on natural circulation in heaving motion 


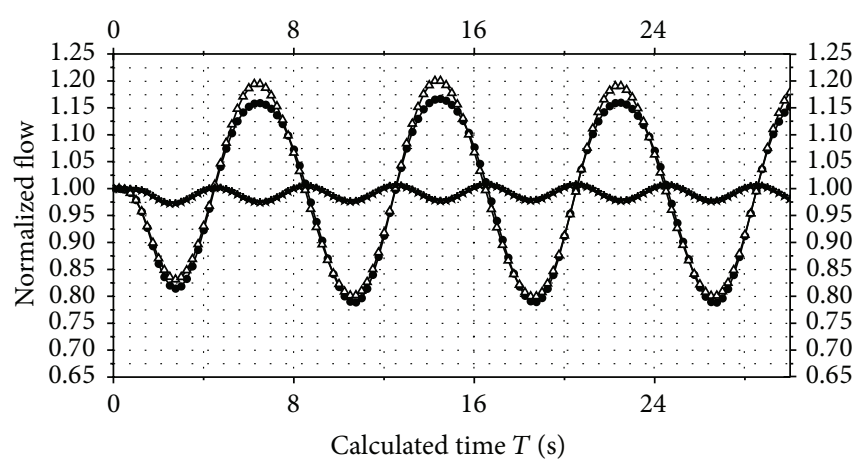

$\rightarrow$ Heaving motion + vertical rolling motion
$\rightarrow-$ Heaving motion only
$\longrightarrow$ Vertical rolling motion only

(a)

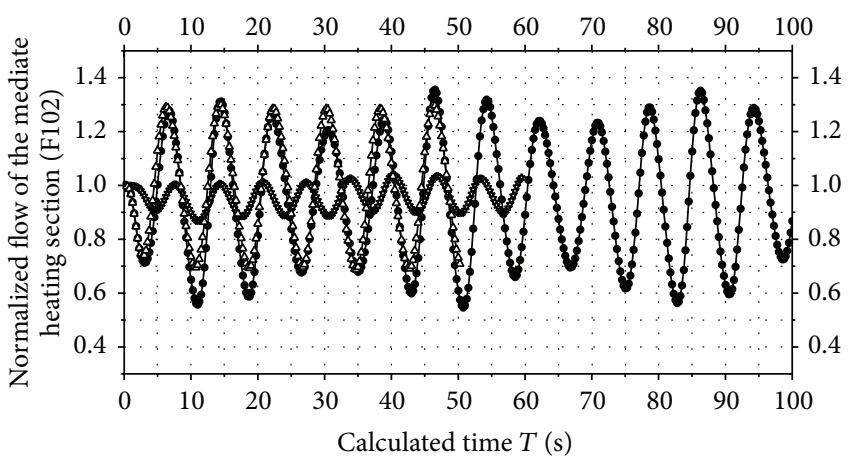

$\rightarrow$ Heaving motion + transverse rolling motion

$\rightarrow$ Transverse rolling motion only

$\triangle$ Heaving motion only

(b)

FIGURE 12: Effect of heaving motion with strength $0.6 \mathrm{~g}$ and cycle $8 \mathrm{~s}$, vertical rolling with swing angle $22.5^{\circ}$ and cycle $8 \mathrm{~s}$, and compound motions consisted of the above two movements on the normalized flow of natural circulation.

were investigated and mechanism of natural circulation in heaving motion was stated. Results indicated the following.

(1) Significant effect of heaving motion on natural circulation was observed. Flow fluctuation would become stronger in heaving motion with long period and high strength.

(2) Slight effect of short-period heaving motion on natural circulation was verified.

(3) Relationship chain of factors affecting natural circulation in heaving motion was given, the alternating field consisted of gravity and additional force, and flow density difference would result in the flow fluctuation of natural circulation.

(4) Long-period heaving motion would lead to more significant influence than inclination and rolling motion and may cause serious accident.

\section{Symbols}

$\begin{array}{ll}k: & \text { Strength of heaving motion } \\ T: & \text { Cycle of motion } \\ \rho: & \text { The density of fluid } \\ f: & \text { Mass force of fluid } \\ \mu: & \text { Flow viscosity } \\ \lambda: & \text { Thermal conductivity of the fluid } \\ S: & \text { Rate of strain tensor } \\ g: & \text { Acceleration of gravity } \\ \vec{f}: & \text { Unit mass force of the fluid } \\ a_{o}: & \text { The acceleration of the additional force } \\ & \text { induced by the translational motion } \\ a_{t}: & \text { The tangential force of fluid } \\ a_{n}: & \text { The normal force of fluid } \\ \psi_{m}: & \text { Swing angle of the rolling motion } \\ w_{d}: & \text { Angular velocity of the periodic heaving } \\ & \text { motion } \\ \Delta P_{d}: & \text { Driving force of natural circulation }\end{array}$

$\Delta \rho(t)$ : Time-varying density difference between the hot fluid and the cold fluid

$V_{o z}: \quad$ Velocity of fluid in $z$ direction

$A_{o z}$ : Displacement of fluid in $z$ direction.

\section{Conflict of Interests}

The authors declare that there is no conflict of interests regarding the publication of this paper.

\section{Acknowledgments}

This work was supported by Project 11072131 of National Natural Science Foundation of China (NSFC) and the Tribology Science Fund of State Key Laboratory of Tribology (Grant no. SKLTKF12B16).

\section{References}

[1] D. Duo and Z. Zhensheng, "5MW Test low-temperature heating reactor put into operation,” Chinese Science Bulletin, vol. 36, pp. 177-182, 1991.

[2] W. Dazhong, D. Dou, and Z. Wenxiang, "Development of the 5WM experimental low temperature nuclear heating reactor and its operational features," Journal of Tsinghua University, vol. 31, pp. 1-11, 1991.

[3] Y. Zhang, D. Zhang, and D. Dong, "Analysis of seawater desalination with NHR-200," Nuclear Energy, vol. 38, no. 1, pp. 21-29, 1999.

[4] Z. Wenxiang and W. Dazhong, "NHR-200 nuclear energy system and its possible applications," Progress in Nuclear Energy, vol. 29, pp. 193-200, 1995.

[5] W. Li, Y. Zhang, and W. Zheng, "Investigation on three seawater desalination process coupled with NHR-200," Desalination, vol. 298, pp. 93-98, 2012.

[6] H. Zhu, X. Yang, H. Gong et al., “Theoretical and experimental study on single phase natural circulation under inclined condition," Journal of Nuclear Science and Technology, vol. 50, pp. 304-313, 2013. 
[7] G. Houjun, Y. Xingtuan, H. Yanping et al., "Study on flow characteristics of integral reactor test facility under rolling motion without heating," Nuclear Power Engineering, vol. 34, pp. 77-81, 2013.

[8] G. Houjun, Y. Xingtuan, and J. Shengyao, "Reactor natural circulation model for a reactor experiencing motion," Journal of Tsinghua University, vol. 53, no. 4, pp. 432-436, 2013.

[9] H.-J. Gong, X.-T. Yang, S.-Y. Jiang, and Z.-Y. Liu, "Theoretical analysis of effect of ocean condition on natural circulation flow," Nuclear Power Engineering, vol. 31, no. 4, pp. 52-56, 2010.

[10] S.-Y. Jiang, X.-T. Yang, H.-J. Gong et al., "Mechanism of natural circulation taking account into heaving movement," Atomic Energy Science and Technology, vol. 43, no. 1, pp. 92-96, 2009. 


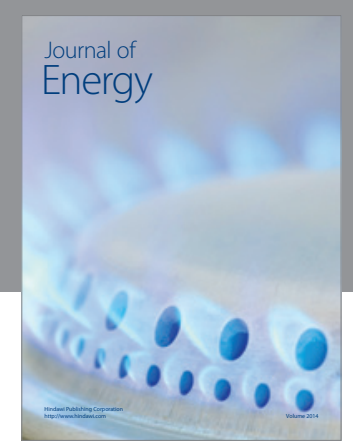

Journal of

Industrial Engineering
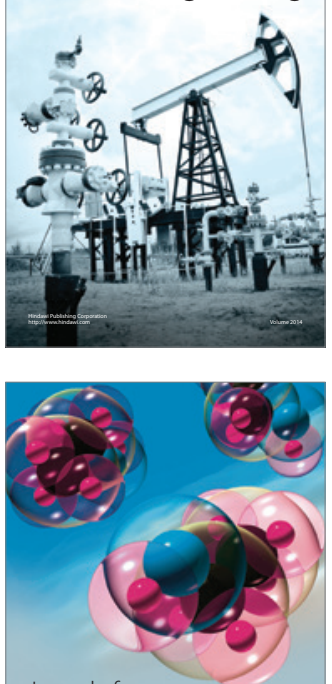

Fuels
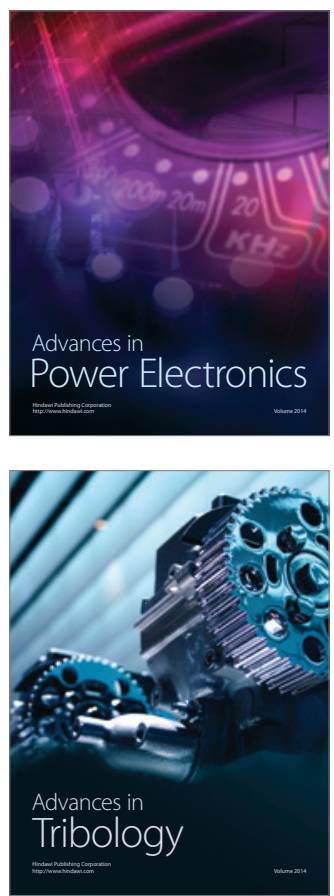

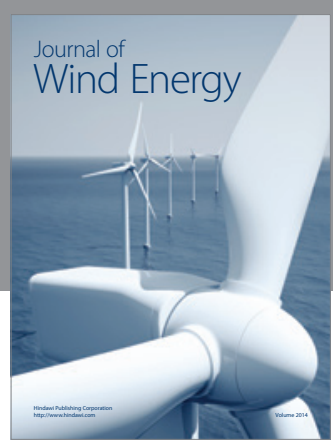

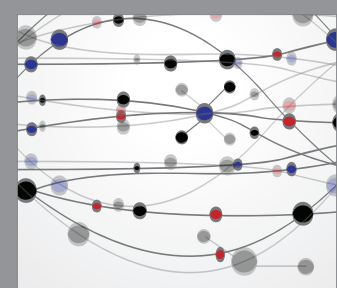

The Scientific World Journal

Submit your manuscripts at http://www.hindawi.com

Journal of

Structures
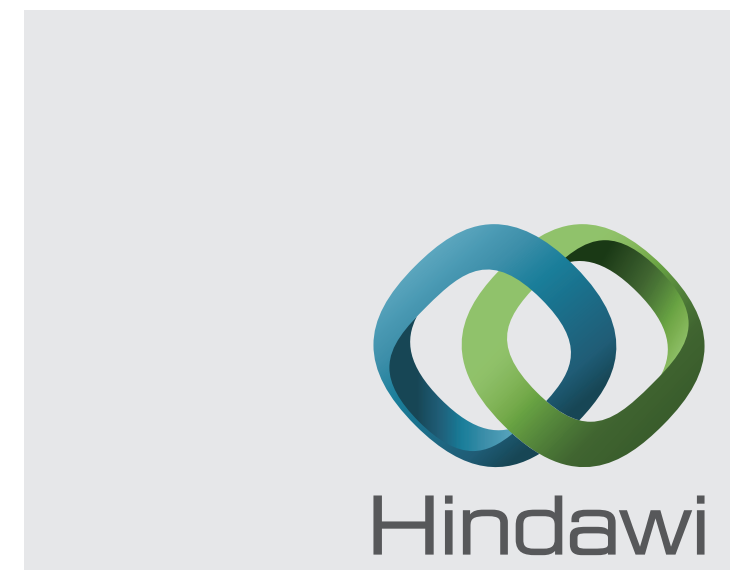

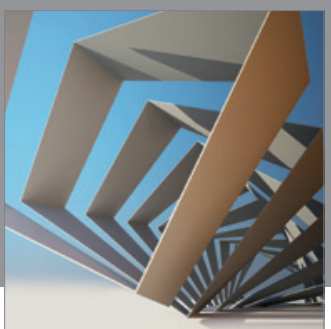

Rotating

Machinery
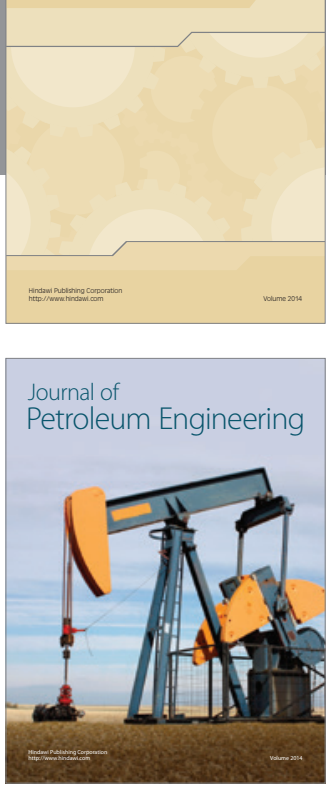

Journal of

Solar Energy
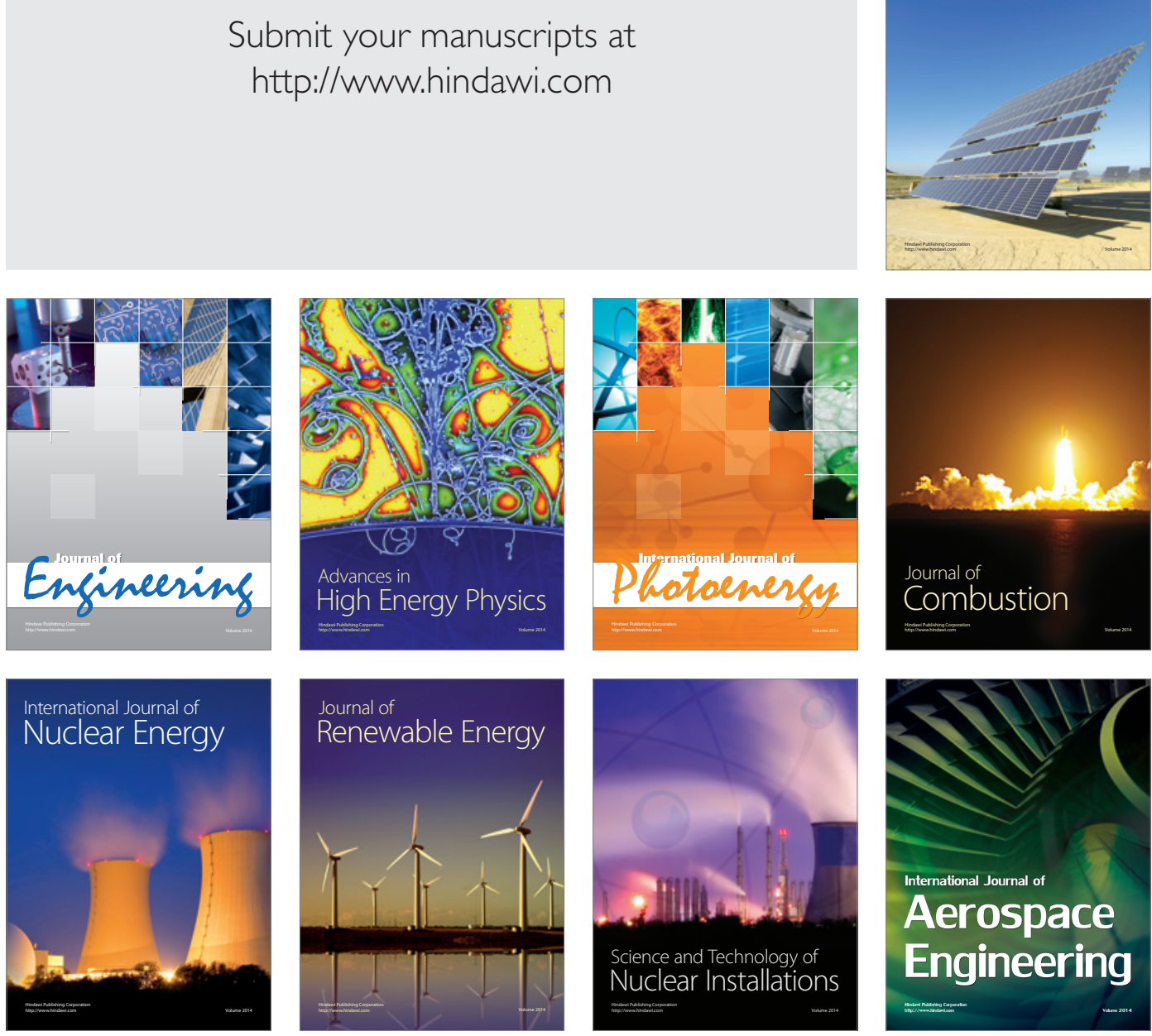